
\title{
23 Research Soure
}

\section{Priority Setting in Planning for Recruitment and Allocation of Healthcare Workers at National and District Level in Zambia}

\section{Mukolima Siluka}

University of Zambia

Adam Silumbwe ( $\sim$ adam.silumbwe@umu.se)

University of Zambia https://orcid.org/0000-0002-1905-5293

Oliver Mweemba

University of Zambia

\section{Research Article}

Keywords: Priority setting, recruitment, distribution, planning, human resource for health and healthcare workers

Posted Date: March 2nd, 2022

DOI: https://doi.org/10.21203/rs.3.rs-1397281/v1

License: (c) (i) This work is licensed under a Creative Commons Attribution 4.0 International License. Read Full License 


\section{Abstract \\ Background}

Priority setting has widely been used in healthcare systems to justify allocation of limited resources such as health services against a huge demand. Zambia, a low-income country is faced with a critical shortage of health workers whose distribution is skewed towards urban areas. This affects effective health service delivery and creates a gap in skills mix. This study therefore sought to explore the priority setting process and its fairness in the planning for recruitment and distribution of health workers in Zambia.

\section{Methods}

This was a qualitative study that collected data using two methods; a document review of national health documents, and interviews $(n=20)$ with district level officers who took part in human resource meetings and decisions. The accountability for reasonableness (AFR) framework was also used to explore fairness and transparency in the processes. Data was analyzed thematically.

\section{Results}

The district level management felt they had limited participation in decision making regarding recruitment and distribution of human resources for health. They felt excluded because most decisions for human resources for health were made at national level. The national level used district vacancies to recruit workers who would later be transferred to other places which perpetuated shortages in the rural districts. Decentralization would help districts have more context-based decisions relating to the human resource challenges they face. Meeting the A4R framework conditions of fairness, transparency and accountability in priority setting proved a challenge as there were mixed feelings from participants in each condition. As a result, fairness and transparency could not be easily determined. The document review highlighted that despite the various strategies put in place to improve transparency, accountability, there continues to be a misalignment between national and district $\mathrm{HRH}$ recruitment and distribution.

\section{Conclusion}

Human resource for health challenges call for more strategies to improve financing for workers, strengthen private sector partnerships and exercise a decentralized approach in order for districts to make human resource decisions that are more relevant to the districts themselves. This will help improve the priority setting process as well as mitigate challenges of mal-distribution.

\section{Background}


Globally, the health sector suffers a number of challenges. These include among others their critical shortage and skewed-distribution of human resources. The shortage is mostly attributed to underfunding towards the health sector, high attrition rates, high workloads, poor human resource management and working environments[1]. Weak human resource management policies and systems contribute to inequitable distribution of existing human resources for health $(\mathrm{HRH})$. In particular, rural areas suffer the most shortages compared to urban areas including under-skilled or untrained staff, thereby contributing to poor health service delivery[2].

Zambia is one of the countries with highest HRH shortages in the world. The World Health Organization (WHO) recommends a minimum of about 2.3 density threshold of physicians per 1000 population. Zambia has only about 1.2 physicians per 1000 population with rural areas suffering the most shortages[3]. Zambia's health system functions with less than half of the required workers for effective delivery of basic health services[4]. The distribution of HRH is skewed towards urban areas[5]. In addition, the country faces a huge disease burden of both communicable and non-communicable diseases and addressing these poses a significant challenge given the shortage of $\mathrm{HRH}[6]$.

The Zambian government strategies to address the HRH challenges as well as accelerate efforts to attain universal health coverage include increasing the number of training facilities and specialties for health professionals $[7,8]$. Other strategies as documented in the governance and management capacity strengthening plan of 2012-2016 include hiring and retaining human resources for health. This has resulted in significant improvements in the numbers of health workers. For example, the government announced in the 2022 budget that 11, 000 human resources for health will be recruited across the country.

Despite the Zambian government making significant progress towards addressing the HRH gap over the years, the challenges regarding recruitment and distribution of $\mathrm{HRH}$ still remain. For example, the HRH decisions on recruitment and distribution are generally centralized at a national level, and may sometimes result in failure to meet the district requirements or fail to address the HRH shortages all together. In particular, these challenges are as a result of the lack of clarity on how to align the national and district level HRH planning systems so as to maximize recruitment and distribution. Further, it is not clear what factors are considered as priority in the process planning for recruitment and distribution of $\mathrm{HRH}$ in the Zambian context.

Priority setting is used to evaluate utilization of limited resources to achieve highest benefits at the lowest costs for essential health care services[9]. Thus, inequity of access to health services justifies the use of priority setting in achieving universal health coverage[10]. Using the Accountability for Reasonableness (A4R) framework, this study therefore sought to explore how priority setting is exercised during the planning for recruitment and distribution of $\mathrm{HRH}[11]$. This was meant to inform policy makers efforts to ensure the process of $\mathrm{HRH}$ recruitment and distribution is much more accountable, transparent and fair, hence seen to be ethically sound, but also seen to respond to national and district level HRH planning process discrepancies. Additionally, the study documents information on the criteria used for recruitment, 
distribution and planning thereby opening way for more studies that may further analyze these processes. This study sought to explore the priority setting process and its fairness in the planning for recruitment and distribution of $\mathrm{HRH}$ at national and district levels.

\section{Methods}

\section{Accountability for Reasonableness Framework (A4R)}

The AFR framework was picked because it promotes fairness and transparency through active involvement of local stakeholders in priority setting. This was the major concern of our study. Local stakeholders play a key role in evidence-based decision-making processes. Decisions made upon evidence impact a positive change to problems that locals face. The AFR framework was developed based on Daniels and Sabin identification of main features of a number of the best performing health care organizations. The framework helps analyze fairness, transparency and accountability in priority setting processes involving various stakeholders. The framework demands satisfaction of its four conditions for a decision making process on priority setting to be fair $[11,12]$.

Firstly, the Relevance condition. This condition emphasizes values and principles to the local setting as decided by agreed criteria. (In the context of this study, to what extent are the districts involved in determining the most relevant decisions made by national level to the district's advantage). Secondly, the Publicizing condition which promotes transparency of priority setting decisions and the reasons behind them. (In the context of this study, does the $\mathrm{MOH}$ headquarter provide reasons for their decisions to allocate health workers as they do, and do they communicate these reasons to the districts). Thirdly the Appeals condition which provides mechanisms for challenging and revising decisions in the light of additional evidence and values from the public. (In this context, do district officers have opportunities to challenge the headquarters decisions?). Finally, the Enforcement condition which demands provision of leadership to ensure that the first three conditions are met.

\section{Study Design}

This study employed a qualitative case study approach which adopted in-depth interviews (IDIs) and document review to collect information. IDIs were used in order for participants to fully describe the planning for recruitment and distribution process of $\mathrm{HRH}[13]$. The reviewed national level documents indicated the successes and failures of various strategies. These strategies aimed to address the HRH shortage and maldistribution as well as to improve transparency in HRH recruitments and distribution. The AFR framework was used to explore fairness and transparency in the recruitment and distribution processes.

\section{Study setting and participants}

With a mix of rural and urban settings as well as new and old district health offices, the study was conducted in four districts as shown in table 1. The disparity in rural and urban towns indicated a better 
comparison on the accountability of the processes. Participants included those who sat in human resource meetings and served at district or provincial hospital level as human resource officers, departmental heads for various health cadres, district health office planners and rural health post sisters in-charge.

Table 1: IDI interviews

\begin{tabular}{|ll|}
\hline District & Number of interviews \\
\hline Limulunga/rural & 3 \\
\hline Lukulu/rural & 3 \\
\hline Lusaka/national & 4 \\
\hline Mongu district health office/urban & 6 \\
\hline Mongu Provincial Hospital/urban & 3 \\
\hline Total & $\mathbf{2 0}$ \\
\hline
\end{tabular}

\section{Sampling Methods}

Purposive and snowball sampling methods were used. Purpose sampling was used because the information gathered could only be obtained from specific people [14], in this case personnel at $\mathrm{MOH}$ district health office and provincial hospital. Snowball sampling was used because participants referred the investigator to other potential key informants. A total of 20recorded interviews were conducted. The sample size was restricted because only a few officers were in the positions responsible for recruitment and distribution of HRH. 3 key informants refused to participate in recorded interviews but were willing to share information. They were however not added to the total recorded interviews.

\section{Data Collection and Document Review}

In-depth interviews were used to collect information guided by an interview guide containing main and probe questions. Further, the A4R framework conditions helped identify important aspects of the study that needed to be emphasized. The interview guide was developed on the basis of the study aim and the A4R framework conditions of fairness and transparency. The data collection exercise lasted for 3 months in all districts. A total of 20 interviews we conducted across the study areas.

The National Health Strategic Plan (NHSP) document that was reviewed as recommended by personnel from $\mathrm{MOH}$ headquarters. Other documents in the review were cited by the NHSP document as related and line documents. These documents contained a history of the HRH crisis in Zambia and the strategies that were put in place. Documents mainly included National Health Strategic Plan (NHSP) 2017-2021, National Human Resource Strategic Plan (NHRSP) 2011-2015, Health Sector profile, $7^{\mathrm{TH}}$ National 
Development Plan (7NDP) 2017-2021 and the Vision 2030 document. The documents informed on the human resource strategies employed to address the crisis. All documents as shown in table 3 were from national level.

\section{Data Analysis}

A thematic analysis of interview transcripts was used to identify deductive themes derived from AFR framework and emergent themes [15]. These helped arrange the data systematically and helped build the coding framework in responding to the gaps identified in the research. Thematic areas according to the A4R framework conditions were also used to analyze the data.

The policy documents were analyzed using the thematic content analysis approach[16]. An excel data grid was developed and data were extracted from the selected policy documents on policy positions regarding HRH in Zambia. These provided information on the various government and stakeholder strategies to address priority setting in the recruitment and distribution of $\mathrm{HRH}$. They indicated the state of transparency and accountability in these processes from district and national level. This enabled us to understand whether the policies provided and an enabling environment satisfy the elements of the A4R framework.

\section{Ethical considerations}

This study received ethical approval from the University of Zambia Biomedical Research Committee (UNZABREC) and the Zambia National Health Research Authority (ZNHRA). The study also received authorisation from the Ministry of Health $(\mathrm{MoH})$ headquarters and the district medical offices in Limulunga and Mongu. Informed consent was obtained from all people who participated in the study.

\section{Results}

The results are presented in two parts. The first part is from the document review which highlights the position of national health strategic documents on increasing transparency and fairness in HRH recruitments and distribution. The second part is based on the findings from key informant interviews. The AFR framework is used to explore the priority setting process in the recruitment and distribution. This was achieved through the four conditions of the framework, relevance, publicizing, appeals and enforcement.

Table 3. Documents and their key policy positions/strategies for $\mathrm{HRH}$ 


\begin{tabular}{|lcl|}
\hline Title & Year & Policy position/strategies for HRH \\
\hline $\begin{array}{l}\text { Vision 2030- } \\
\text { Republic of Zambia }\end{array}$ & 2006 & $\begin{array}{l}\text { Ensure equitable access to quality care for all through reduction of } \\
\text { population/doctor and population/nurse ratio from 17, 589 to 5000 } \\
\text { and from 1, 864 to 700 by 2030 respectively. }\end{array}$ \\
\hline $\begin{array}{l}\text { National Human } \\
\text { resources for health } \\
\text { strategic plan } \\
\text { (2011-2015) }\end{array}$ & 2011 & $\begin{array}{l}\text { Prioritize needs and activities relating to HRH crisis by providing a } \\
\text { clear, feasible, affordable and coherent framework }\end{array}$ \\
\hline $\begin{array}{l}\text { Health sector } \\
\text { profile }\end{array}$ & 2013 & $\begin{array}{l}\text { Emphasizes private sector collaboration with government to improve } \\
\text { HRH recruitment and provision of health services in addressing the } \\
\text { HRH critical shortage. }\end{array}$ \\
\hline $\begin{array}{l}\text { National health } \\
\text { strategic plan } \\
\text { (2017-2021) }\end{array}$ & 2017 & $\begin{array}{l}\text { Improve availability and distribution of qualified HRH, strengthen HR } \\
\text { management to improve efficiency, effectiveness and service } \\
\text { delivery. Significantly increase and promote quality training } \\
\text { institutions to mitigate shortage. }\end{array}$ \\
\hline $\begin{array}{l}\text { Seventh national } \\
\text { development plan } \\
\text { 2017-2021 }\end{array}$ & 2017 & $\begin{array}{l}\text { Coherent, efficient, and effective HRH training and recruitment } \\
\text { mechanisms to improve health workforce capacity development; } \\
\text { recruitment and retention enhancement; deployment; and } \\
\text { competence and quality assurance enhancement. }\end{array}$ \\
\hline $\begin{array}{l}\text { Human resources } \\
\text { for health planning } \\
\text { \& development } \\
\text { strategy framework }\end{array}$ & 2017 & $\begin{array}{l}\text { Recognizes that continuous political, institutional and financial } \\
\text { assurance with participation of different key stakeholders and } \\
\text { partners that can impact HRH production, availability and } \\
\text { performance is critical to improving HRH planning and development. }\end{array}$ \\
\hline
\end{tabular}

Various strategies to address the HRH challenges in Zambia have been stipulated in key health sector policy documents. These documents highlight critical priority setting aspects shaping the recruitment and distribution of $\mathrm{HRH}$ processes such as the needs-based approach, promotion of accountability and transparency as well as formalizing the role of community structures in HRH recruitment. However, the strategies to address $\mathrm{HRH}$ challenges in Zambia do not clearly state the role of priority setting in achieving fair recruitment and distribution of $\mathrm{HRH}$. Further, despite the policy documents indicating that the district level should be the central focus in HRH decision making, there are no clear linkages and outlined roles between district and national level in implementing these strategies.

\section{Recruitment process of human resources for health in Zambia}

Recruitment was both bottom-up and top-down approach. The latter was said to be more prominent. The district health officers' role in both approaches was mainly to recommend for positions or promotions based on experience, competence or length of service of volunteers or workers. Nonetheless, human resource officers also reported that despite the recommendations they made, higher levels rarely adhered to the recommendations. This highly demotivated the volunteers at the local facilities. 
"...some of our recommendations are not taken into consideration. We will recommend and then we just see people that we didn't recommend coming to sit on those positions, and those that are volunteering of course usually it's very demotivating that you have been volunteering and then you just see someone else coming to report and you're not considered for a job... (IDI 13, Human Resource Officer)

District level staff further argued that the non-adherence of district recommendations by national level resulted in lost time for building good community relations between the community members and the health workers. This resulted in disruption of services within a particular facility. Volunteers usually already had strong community partnerships because they understood the community's way of life as compared to the newly employed who had to take time in building these community relations. The community members also took time to establish trust in the newly employed healthcare workers.

"...they have the technical knowledge but they will need to start building the community partnerships they'll need to start understanding the community... Of course you are trained to build but you lose time in building... It will take time to acclimatize to the environments, the people, the language, the Culture, the traditions and the people to trust you so that they say ok if I have a problem I can come to this person" (IDI 6, Clinical Officer HOD)

The district staff preferred that their HR recommendations to provincial and national levels be adhered to. They stated that a bottom-up or more decentralized approach to HRH recruitment should take precedence because the lower levels of the health system were more acquainted to the local HR challenges than the national level. This was also seen as a way that would facilitate better health outcomes for both the health system and the community because interventions would be specific to district needs.

As I earlier on alluded to say that it was going to be much more if we decentralized that recruitment can only be done at grass-root level, at district-level that would be much better because at district level we understand how our facilities are in terms of the need." (IDI 9, District Planning HOD)

Some study participants reported that there were priority considerations that directed the recruitment process at district and national level. These included staff facility needs, treasury authority, vacancies and new positions determined by human resource committees. Participants reported that the recruitment of health workers was dependent on these considerations because of their importance. For example, the number of health workers was limited by financial constraints, the demand for services necessitated the need for new positions and also the need to fill vacancies that arose.

"...the recruitment of health workers usually is done centrally in most of the Times is done centrally. You would find that ministry of health will ask for treasury authority to recruit... And if the recruitment is done from our end here, for instance a position falls vacant maybe by death or by promotion or someone has resigned, in human resource we always have committees so you would find that we discuss such issues in the human resource management committee..." (IDI 3, Nursing HOD) 
"So, the Recruitment is determined by need... and we will also look at other issues depending on the staff... but you also look certain facilities if it is in the rural areas, do we have the accommodation for the staff and all those things. But otherwise, the process is that first of all you know where your need is." (IDI 8, Environmental Health HOD)

Table 4: Recruitment process at various administrative levels of the health system

\begin{tabular}{|c|c|c|}
\hline \multirow[b]{2}{*}{ Level } & \multicolumn{2}{|l|}{ Role in recruitment } \\
\hline & Top-down approach & Bottom-up approach \\
\hline Facility & $\begin{array}{l}\text { Conducts needs HR assessment to } \\
\text { determine gaps submitted to district level }\end{array}$ & $\begin{array}{l}\text { Recommends volunteers at facility level to } \\
\text { district level }\end{array}$ \\
\hline District & $\begin{array}{l}\text { Consolidates HR facility submissions \& } \\
\text { compares with staff establishment to } \\
\text { determine district gaps submitted to } \\
\text { provincial level }\end{array}$ & $\begin{array}{l}\text { Recommends volunteers/staff for } \\
\text { positions/promotions to provincial level. }\end{array}$ \\
\hline Provincial & $\begin{array}{l}\text { Either consolidates district submissions \& } \\
\text { compares with staff assignment to } \\
\text { determine provincial gaps submitted to } \\
\text { national level or conducts mass } \\
\text { recruitments }\end{array}$ & $\begin{array}{l}\text { Honor/dishonor district recommendations, } \\
\text { may make their own recommendations for } \\
\text { promotions/positions to national level }\end{array}$ \\
\hline National & $\begin{array}{l}\text { Either conducts mass recruitments or } \\
\text { consolidates provincial submissions to } \\
\text { determine national level gaps forwarded } \\
\text { to public service management division } \\
\text { (PSMD) }\end{array}$ & $\begin{array}{l}\text { Honor/dishonor district/provincial } \\
\text { recommendations for } \\
\text { promotions/positions or create new } \\
\text { positions \& deploy staff to } \\
\text { province/district without consulting lower } \\
\text { levels. }\end{array}$ \\
\hline PSMD & $\begin{array}{l}\text { Permits recruitment subject to treasury } \\
\text { authority from Ministry of Finance }\end{array}$ & \\
\hline
\end{tabular}

\section{Distribution process of human resources for health in Zambia}

The district level administration had more control over the distribution process of $\mathrm{HRH}$ once staff were assigned from the national level. The national level distributed healthcare workers to provinces or districts not only according to the number of recruits, but also the staffing levels indicated by the province or district themselves. Upon receiving staff, the local level would not entirely consider the facility or district indicated in the letter of appointment but would redirect according to the need per facility or district. Study participants identified some of the major considerations which included staff needs and accommodation, information from program officers, staff qualification against posting, geographical location, patient to health worker ratio, gender and social needs and population density.

"...ok because when we receive new staff, we are responsible for deployments so we'll take them to needy facilities, so we'll sit down before sending people into the facility, we'll look at which area needs which 
cadre and then we'll deploy depending on the outcome of our meetings. So, we'll not send people by looking at what facility is indicated on their letter of appointment, so we'll sit down and assess which facilities need which cadres and then we'll send..." (IDI 13, Human Resource Officer).

\section{Planning process of human resources for health and community engagement}

Community engagement was stated to be one of the main dimensions in the planning process of HRH. Staff from rural health facility level indicated that community engagement was facilitated by community health groups (CHG) such as safe motherhood group (SMAGs) and other community health workers (CHW). CHG gave weekly and monthly reports to the health facility. These reports included the community health challenges realized through neighborhood health committee meetings. Secondly, the facilities conducted the outreach plan and determined the $\mathrm{HRH}$ needs by looking at indicators which demanded human resource interventions for specific health challenges within the district. This enabled the rural health facilities to plan for $\mathrm{HRH}$ and submit to higher levels for approval. The other dimension of the planning process was the clinical work of the community. Therefore, planning was reported to begin from the lower level of the health system, the community.

"... Most of the things they happen in the community so deliberately there's this group that has been put in place that act like eyes for the facility in the community. They are able to address issues that seem to be troubling the community that we may not be aware of then they bring them at the facility level we pick them as well, we take them at the district level just like that it goes higher. (IDI 12, Health post Nursing $H O D)$

The district health staffs as well as the document review indicated that in the planning process for human resources, the district level planning was designed to feed into the National Health Strategic Plan priorities for $\mathrm{HRH}$. This was done by tailoring the district programs towards the strategic plan priority areas, highlighting that district level planning was rather directed by national level priorities.

"So as the district we feed into that strategic plan and then tailor the programs towards that so that what we achieve as a district according to the strategic plan behind us, then it means we would have contributed to the national plan." (IDI 4, Pharmacy HOD)

In both approaches to the planning process, staff from rural facility level indicated that execution of the plans at facility level which mainly revolved around service delivery and mother and child health was however a major challenge in the outskirts. This was because of the acute human resource deficit with retention challenges and inappropriate skills mix thereby leading to unsatisfactory service delivery. Some district HR and planning officers also described the planning process as inconsistent, time consuming and too short. Further, the attention and importance that the planning process required was also reported to be inadequately addressed.

"In an outskirt facility you'd find like there's only one staff available that is supposed to do all the activities at the facility like the way I was. I was alone at the facility for 3 years to see all the departments 
and just satisfy them so some of the targets I might fail to reach them because of manpower." (IDI 12, Health Post Nursing HOD)

"...the cycle itself has not been consistent, sometimes it's, you know you'd start in May like this year we are in August...then also we have issues where maybe the people that are doing the actual plans at the facility level are not well-versed with the planning process itself, yeah, we have new staff that are coming in, old ones have left and maybe we've not had time to orient them on how to go about the planning, yeah so the whole process may be new to them and they might not know or even attach the Importance that the planning deserves..." (IDI 13, Human Resource Officer)

\section{Accountability for reasonableness framework}

\section{Relevance condition}

Some participants in rural areas felt that the HR processes were not relevant to the district health needs. This was because some staff that were distributed from national level would later be transferred elsewhere to more urban towns hence, the district positions were only used to recruit people. Additionally, the district role was said to be very limited because the non-adherence to district recommendations at national level could not be over ruled by the districts. In this regard, some respondents felt the system was not very responsive to the district needs

"You can't overrule what the ministry has already recommended because you are too junior to overrule. So, our role actually is very limited in terms of recruitment... the people that are sent from central level they give us a lot of problems. Sometimes you find that the moment this person reports they'll start thinking of going back. So, it's more less like we are just here, our positions are just being used to recruit people. Once they are recruited, they are redirected somewhere else." (IDI 5, Human Resource Officer)

Some respondents reported that recruitment, planning and distribution systems were alright but implementers corrupted the system because it was not followed to the latter. Unspecified external influences were seen as the major reasons that influenced the implementers in adulterating the system. As a result, certain service demands were not met according to the need that were identified.

"...the system itself I think the system is ok I would say that mainly the people have sort of corrupted the system, the processes are not being followed to the latter. We have a very good system in place recruitment process all the way up to distribution and things like that but then we have external influences that obviously will deter us from doing the correct things so the system is there but I think it's been adulterated, yeah." (IDI 13, Human Resource Officer)

On the contrary, some participants expressed that the HR system was relevant to district needs because there was an observed increase in staffing levels. This indicated a huge improvement within the ministry in terms of recruitments. Additionally, there was an observed increase in the community health agenda that emphasized the community engagement practice which focused more on preventive than curative approach to public health.

Page $11 / 18$ 
"There is a huge improvement as I have already told you that we are seeing a tremendous improvement on the levels of staffing and the system is also responding by looking on how we can effectively work with people themselves... And the ministry is driving the community health agenda very strongly such that we are working on developing our systems to such an extent that we become more preventive in our approach than being curative." (IDI 11, District Health Officer)

\section{Publicizing condition}

It was reported that national level did not give any justifications to the lower levels for the HR decisions they made in recruitment or distribution processes. Some participants that headed departments indicated that there was no established channel of communication for justifications between district and national level. As a result, not only were volunteer workers demotivated but some district officers also opted to stop recommending them for employment due to national level not adhering to district recommendations.

"No reason. Sometimes they just send (laughs)...these graduates were recommended but central level just sent someone, so l've stopped recommending because what we recommended, someone else has come from Lusaka when they saw that the vacancy, so that's the challenge." (IDI 10, Environmental Health Specialist)

\section{Appeals condition}

Some district level human resource officers highlighted that they wrote to national level to appeal for positions and or recommendations. However, national level did not consider the district appeals accordingly in most instances. It was rare that national level would give feedback to the district despite the requests for staffing levels that the national level makes to the district level. It was indicated that there was no room for appeals between the district and national level hence, the district level just received staff and distributed them accordingly.

“...we write through PHO to Ndeke House but it's rare that we receive feedback. When you follow, they will tell you that you wait when we have new treasury authority, we are going to consider what you have submitted. But when the new TA comes, they won't even consider your list. Every year the ministry requests us to submit our needs in terms of the staffing, which positions do you want to be created, which positions do you want to be funded, we do that although when the final authority comes, they don't follow our submissions in most cases, they don't follow our submissions." (IDI 5, Human Resource Officer)

\section{Enforcement condition}

The human resource department at district level was reported to be the office in charge of enforcing the appeals and publication from district level to the national level. This was done in the reports submitted to the district human resource officer from facilities and departmental heads at district level which were forwarded to higher levels. Apart from the reports submitted, the facility level staff also reported that physical contact with the district human resource officers was sometimes done to emphasize the 
importance of having more staff at the facility level. Nevertheless, enforcement remained a challenge at district level due to the limited roles of the district. Most decisions from national level came as final decisions.

"...So the HR office will receive that report and they will note that ok there is reduction in manpower at such and such a facility so need to put manpower...sometimes they get busy and they can have an oversite over those issues, so you have to go there personally and express the pains that you have because there's quite, the work is just overwhelming and depressing so if you don't speak sometimes it will just go like that so you need to go to give some pressure on the HR office so that they can employ more staff." (IDI 12, Health Post Nursing HOD)

\section{Discussion}

This study found that national level did not adhere to district recommendations on HRH. Additionally, the national level used district vacancies to only recruit workers who would later be transferred to other places. This disrupted quality health service delivery and perpetuated the rural district HRH shortages. As a result, participants felt a need for decentralizing the decision-making process in recruitment and distribution in order to adequately address district challenges. Our study further found that the priorities that are considered in all processes proved vital as they highly contributed to the quality-of-service delivery. Meeting the A4R framework conditions proved a challenge as there were mixed feelings from participants in each condition. As a result, fairness and transparency could not be easily achieved. The document review highlighted that despite the various strategies put in place to improve transparency, accountability, $\mathrm{HRH}$ recruitment and distribution, there is still need to provide further guidance.

While it is commendable that the recruitment process gives room for district levels to submit the HRH district requirements, it is however questionable that the district recommendations are not adhered to by national level. With the centrally controlled nature of the HRH recruitment and distribution process, the local actors felt the system was corrupted by some officials hence crippling the full functionality of district level decision making process. Two Kenyan studies similarly found that unclear communication channels between national and district authorities led to a mistrust between actors at both levels with regards to HRH recruitment[17, 18]. This limits capacity building, guidance roles and responsibilities for decision-making actors at district and community levels. This hindered priority-setting processes and allowed space for opportunistic actors to seize power and contribute to selected personal priorities such as political re-election[19]. Implementation and decision making done at national level entails closed door meeting which makes the local level officers feel alienated from the decisions. This results in irregularities with regards to rendering quality services.

The above findings contrast with a systematic scoping review study and finding in England which showed that prioritization of contextually relevant evidence sourced from local actors by decision makers led to increased positivity and proved to be more useful than other forms of evidence-based sources[20]. In this view, it is important to strengthen capacity building at both levels which may in turn add value and 
authority to the district level in the decision-making process of the $\mathrm{HRH}$ recruitment aimed to respond to the district needs. It is also vital to develop policies that will enable the district level to have full authority on those employed under their jurisdiction in order to avoid abrupt interruption of quality health services.

Our study indicated that the planning was a two-way approach, bottom-up approach and that the district level fed into the national health strategic plan aspirations. A key ethical question thence arises, should lower-level priorities direct higher-level priorities or vice versa?[21]. This study argues that lower-level priorities should direct higher-level priorities due to the diverse health needs of local settings. It was however noted that this had not been the case. Instead of local based evidence, this study indicated that some determiners of human resource interventions were directed mainly by the political and economic indicators[22].

Some respondents felt the systems of recruitment, distribution and planning were not relevant to the district needs because decisions made by national level were not obliged to adhere to the district requests[23]. A review aiming to examine the extent of stakeholder involvement in decision making processes found that in practice, not all stakeholders participate in priority-setting processes as envisioned by the frameworks[24]. Further, HRH gaps and rejected plans at district level were a result of the national level's incapability to fund them hence not adequately responding to the district needs. Studies done in Ghana and Zambia indicated that district health managers acknowledged that funds are a major limitation in ensuring efficient and effective service delivery at district level. Due to insufficient funds for $\mathrm{MOH}$ sourced from ministry of finance, deployment of health workers was limited[25].

Low efficiency in the process of leadership has proved to produce low technical and institutional capacity of $\mathrm{HRH}[26]$. Decentralization can nonetheless improve communication and financing of activities at district level which may in turn strengthen $\mathrm{HRH}$ recruitments and distribution[27]. However, a Tanzanian study indicated that recruitment under a decentralized system was characterized by complex bureaucratic procedures and failures or severe delays to get the required $\mathrm{HRH}$. Further, decentralization proved more expensive and difficult to recruit specialized $\mathrm{HRH}$. Centralization system on the other hand proved effective in recruiting qualified staff and balancing their distribution across districts though poor in ensuring retention of employees[28]. Therefore, if decentralization of $\mathrm{HRH}$ recruitment is adopted, strong policies will be imperative in order to adequately address the challenges that come with it.

\section{Study strength and limitations}

This was a qualitative study which provided detailed first-hand information. Additionally, the sampled districts had rural and urban environmental settings making the findings of this research more valid on comparative basis. Further, various participants in different capacities took part in this research thereby collecting information from different perspectives. Despite using national level data from document review, the interviews did not include key national level officers involved in the planning for recruitment and distribution for HRH. Hence, comparative basis between district and national level views in the theoretical approach of this study may have been limited. Also, some participants refused to be recorded 
hence the sample was affected due to the limited officers responsible for $\mathrm{HRH}$. It is also difficult to generalize the findings because compared to the number of districts in the country, this study only involved four districts indicating a smaller sample size. The results are however transferable

\section{Conclusion}

While the priorities that are considered in the processes have proved to be vital, it is however important to note that the priority setting process in all the recruitment, distribution and planning processes for human resource for health require further attention in the engagement of the district health officers. Additionally, if decentralization is taken as a way forward, it will require adequate time invested in preparing for it so that its purpose can be fully achieved with clear plans and strategies to successfully implement it in an attempt to address HRH challenges in Zambia. There is also need to strengthen and formulate policies that will create a clear roadmap to promote fairness and transparency in the processes.

\section{List Of Abbreviations}

$\mathrm{HR}$

Human Resource

$\mathrm{HRH}$

Human Resource for Health

$\mathrm{MOH}$

Ministry of Health

$\mathrm{NHRH}$

National Human Resource for Health

NHSP

National Health Strategic Plan

WHO

World Health Organization

7NDP

Seventh National Development Plan

\section{Declarations}

\section{*Ethic Approval}

Ethical clearance for this study was granted by the University of Zambia biomedical research ethics committee (UNZABREC) and National Health Research Authority (NHRA). Ministry of health headquarters, the provincial health offices of Lusaka and Western provinces and the district health offices of all study sites permitted data collection from the sites. Privacy was respected at every step; participants were free to withdraw or not respond to any questions that they considered sensitive or made them uncomfortable. 


\section{*Availability of data and material}

All data that was analyzed and/or used in this study is public and available on google.scholar.com and ministry of health Zambia.

\section{*Competing interest}

The authors declare that they have no competing interests.

\section{*Funding}

The funding of this study was by the author for academic purposes.

\section{*Author's contribution}

MS collected data and conducted an initial analysis of the interview transcripts and documents reviewed. AS supervised the study process and analyzed the data further. OM performed a final analysis of data and also supervised the study. All authors read and approved the final manuscript.

\section{*Acknowledgements}

We would like to acknowledge the department of health policy and management in the school of public health at the University of Zambia for the professional guidance and encouragements.

\section{References}

1. Flynn WJ, Valentine SR, Meglich P. Healthcare human resource management. Cengage Learning. [cited Available from; 2021.

2. Organization WH, Global strategy on human resources for health: workforce 2030. 2016.

3. Schatz JJ. Zambia's health-worker crisis. The Lancet. 2008;371(9613):638-9.

4. Ferrinho $P$, et al. The human resource for health situation in Zambia: deficit and maldistribution. Hum Resour health. 2011;9(1):1-11.

5. Vledder M, Campbell K. The human resources for health crisis in Zambia: an outcome of health worker entry, exit, and performance within the national health labor market. World Bank Publications. [cited Available from;; 2011.

6. Tjoa A, et al. Meeting human resources for health staffing goals by 2018: a quantitative analysis of policy options in Zambia. Hum Resour health. 2010;8(1):1-10.

7. Shen GC, et al. Incentives to change: effects of performance-based financing on health workers in Zambia. Hum Resour health. 2017;15(1):1-15.

8. Prust ML, et al. Assessment of interventions to attract and retain health workers in rural Zambia: a discrete choice experiment. Hum Resour health. 2019;17(1):1-12. 
9. Baltussen $\mathrm{R}$, et al. Priority setting for universal health coverage: we need evidence-informed deliberative processes, not just more evidence on cost-effectiveness. Int $\mathrm{J}$ health policy Manage. 2016;5(11):615.

10. Chalkidou K, et al. Priority-setting for achieving universal health coverage. Bull World Health Organ. 2016;94(6):462.

11. Daniels N, Sabin JE. Accountability for reasonableness: an update. Bmj, 2008. 337.

12. Menon D, Stafinski T, Martin D. Priority-setting for healthcare: who, how, and is it fair? Health Policy. 2007;84(2-3):220-33.

13. Merriam SB, Tisdell EJ. Qualitative research: A guide to design and implementation. John Wiley \& Sons. [cited Available from; 2015.

14. Gentles SJ, et al. Sampling in qualitative research: Insights from an overview of the methods literature. qualitative Rep. 2015;20(11):1772-89.

15. Braun V, Clarke V. Reflecting on reflexive thematic analysis. Qualitative Res Sport Exerc Health. 2019;11(4):589-97.

16. Neuendorf KA. Content analysis and thematic analysis. In: Advanced research methods for applied psychology. Routledge; 2018. pp. 211-23. [cited Available from;

17. Adano U. The health worker recruitment and deployment process in Kenya: an emergency hiring program. Hum Resour Health. 2008;6(1):1-3.

18. Munywoki $\mathrm{J}$, et al. Tracking health sector priority setting processes and outcomes for human resources for health, five-years after political devolution: a county-level case study in Kenya. Int $\mathrm{J}$ Equity Health. 2020;19(1):1-13.

19. Barasa EW, et al. The influence of power and actor relations on priority setting and resource allocation practices at the hospital level in Kenya: a case study. BMC Health Serv Res. 2016;16(1):113.

20. Kneale D, et al. The use of evidence in English local public health decision-making: a systematic scoping review. Implement Sci. 2017;12(1):1-12.

21. Mueller CE. Examining the inter-relationships between procedural fairness, trust in actors, risk expectations, perceived benefits, and attitudes towards power grid expansion projects. Energy Policy. 2020;141:111465.

22. Dol J, et al. The inclusion of mothers in human resources for health planning. Int Nurs Rev. 2020;67(1):101-8.

23. Wagner $\mathrm{M}$, et al. Moving towards accountability for reasonableness-a systematic exploration of the features of legitimate healthcare coverage decision-making processes using rare diseases and regenerative therapies as a case study. Int J health policy Manage. 2019;8(7):424.

24. Razavi SD, et al. Applying priority-setting frameworks: A review of public and vulnerable populations' participation in health-system priority setting. Health Policy. 2020;124(2):133-42. 
25. Portela GZ, et al. Human resources for health: global crisis and international cooperation. Ciencia \& saude coletiva. 2017;22:2237-46.

26. Wu J, Yang Y. Inequality trends in the demographic and geographic distribution of health care professionals in China: Data from 2002 to 2016. Int J Health Plann Manag, 2019. 34(1): e487-508.

27. McCollum R. Process, power and politics: setting priorities for community health and equity in the recently devolved Kenyan health system. The University of Liverpool (United Kingdom; 2017. [cited Available from;

28. Malema RN, Muthelo L. Literature review: Strategies for recruitment and retention of skilled healthcare workers in remote rural areas. EQUINET (Harare) and University of Limpopo (South Africa) Report, 2018(115). 